University of Nebraska - Lincoln

DigitalCommons@University of Nebraska - Lincoln

1997

\title{
Preferential Bonding Orientations of Ferrocene on Surfaces
}

C. Waldfried

D. Welipitiya

C. W. Hutchings

H. S. V. de Silva

Gordon A. Gallup

University of Nebraska-Lincoln, ggallup1@unl.edu

See next page for additional authors

Follow this and additional works at: https://digitalcommons.unl.edu/physicsdowben

Part of the Physics Commons

Waldfried, C.; Welipitiya, D.; Hutchings, C. W.; de Silva, H. S. V.; Gallup, Gordon A.; Dowben, Peter A.; Pai, W. W.; Zhang, Jiandi; Wendelken, J. F.; and Boag, N. M., "Preferential Bonding Orientations of Ferrocene on Surfaces" (1997). Peter Dowben Publications. 227.

https://digitalcommons.unl.edu/physicsdowben/227

This Article is brought to you for free and open access by the Research Papers in Physics and Astronomy at DigitalCommons@University of Nebraska - Lincoln. It has been accepted for inclusion in Peter Dowben Publications by an authorized administrator of DigitalCommons@University of Nebraska - Lincoln. 


\section{Authors}

C. Waldfried, D. Welipitiya, C. W. Hutchings, H. S. V. de Silva, Gordon A. Gallup, Peter A. Dowben, W. W. Pai, Jiandi Zhang, J. F. Wendelken, and N. M. Boag 


\title{
Preferential Bonding Orientations of Ferrocene on Surfaces
}

\author{
C. Waldfried, D. Welipitiya, C. W. Hutchings, H. S. V. de Silva, G. A. Gallup, and \\ P. A. Dowben* \\ Department of Physics and Astronomy and Center for Materials Research and Analysis, University of \\ Nebraska-Lincoln, Lincoln, Nebraska 68588-0111
}

\author{
W. W. Pai, Jiandi Zhang, and J. F. Wendelken \\ Solid State Division, Oak Ridge National Laboratory, Oak Ridge, Tennessee 37831-6030
}

\author{
N. M. Boag \\ Department of Chemistry, Salford University, Salford, M5 4WT England
}

Received: July 30, $1997^{\otimes}$

\begin{abstract}
We have measured the molecular orientation and bonding of adsorbed ferrocene on $\operatorname{Ag}(100)$ and $\mathrm{Cu}(100)$ using angle-resolved photoemission spectroscopy (ARPES). The results for molecular adsorption on $\operatorname{Ag}(100)$ are complemented by high-resolution electron energy loss spectroscopy (HREELS) measurments and ab initio calculations for the ferrocene vibrational modes. The measurements indicate that ferrocene adsorbs on $\operatorname{Ag}(100)$ with the molecular axis perpendicular to the surface. In contrast, as indicated using ARPES and scanning tunneling microscopy, ferrocene adsorbed on the $\mathrm{Cu}(100)$ surface is oriented with the molecular axis parallel with the surface. Model calculations allow us to assign all of the observed vibrational modes for the weakly bound molecular ferrocene on $\operatorname{Ag}(100)$ - both dipole and impact scattering modes have been observed.
\end{abstract}

\section{Introduction}

Metallocenes, including ferrocene (schematically shown in Figure 1), are central to inorganic organometallic chemistry and are important catalysts. ${ }^{1}$ Metallocenes have also been recently used as metallization sources, ${ }^{2-4}$ but as yet only a few studies with a focus on the surface chemistry of metallocenes exist. ${ }^{5-7}$ Ferrocene, $\mathrm{Fe}\left(\mathrm{C}_{5} \mathrm{H}_{5}\right)_{2}$, has been demonstrated to adsorb molecularly on $\operatorname{Ag}(100)$ at low temperatures ${ }^{5,6}$ as a weakly bound molecular adsorbate. ${ }^{5}$

As noted in recent reviews, ${ }^{8,9}$ electron spectroscopies in conjunction with dipole selection rules and symmetry arguments may be used to study the preferential bonding orientation of large molecular adsorbates on surfaces. The use of symmetry and selection rules in determining molecular orientation originally focused on small, diatomic molecules such as $\mathrm{CO}, \mathrm{N}_{2}$, and NO on metal and semiconductor surfaces. The use of angleresolved photoemission (ARPES) has been extended to determine the preferential surface bonding orientation of large organics, ${ }^{8-10}$ main group cluster molecules ${ }^{8,11}$ and organometallics. ${ }^{8,9,12}$

Although ARPES is a powerful tool for studying molecular adsorbates, it has several limitations. The application of symmetry and selection rules to photoemission may not always uniquely define the adsorption site. Furthermore, photoemission tends to be insensitive to dehydrogenation in large molecules. Thus, high-resolution electron energy loss spectroscopy (HREELS) is an excellent complementary spectroscopy. There is also the complication that the adsorbed ferrocene species could adopt either one of the two possible local symmetry configurations: $D_{5 d}$ or $D_{5 h}$ (as shown in Figure 1). Of course, interaction with the substrate will lead to a reduction in the absolute point group symmetry.

* Address all correspondence to this author.

${ }^{\otimes}$ Abstract published in Advance ACS Abstracts, September 15, 1997.

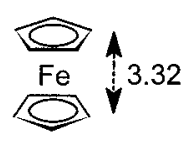

(a)

$\mathrm{Cu}(100)$

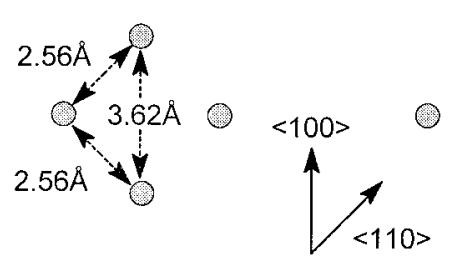

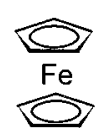

(b)

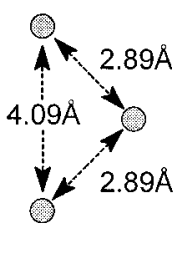

$\operatorname{Ag}(100)$
Figure 1. The two configurations of ferrocene: (a) staggered configuration of $D_{5 d}$ symmetry and (b) eclipsed configuration of $D_{5 h}$ symmetry. The schematic of the surface lattice of both $\mathrm{Cu}(100)$ and $\operatorname{Ag}(100)$ is also shown.

\section{Experimental Section}

The angle-resolved photoemission spectra (ARPES) were acquired at the Synchrotron Radiation Center in Stoughton, WI. The light was dispersed using the $6 \mathrm{~m}$ toroidal grating monochromator (TGM), and several photon energies were used. The ultrahigh-vacuum chamber was equipped with an angleresolved hemispherical electron energy analyzer which has an acceptance angle of $\pm 1^{\circ}$, as described elsewhere. ${ }^{13}$ The combined energy resolution of the analyzer and the light source was approximately $150 \mathrm{meV}$ or less. The light polarization dependence of the photoemission spectra was studied at two light incidence angles: $70^{\circ}$ off-normal (p-polarized light) and $40^{\circ}$ off-normal $((\mathrm{s}+\mathrm{p})$-polarized light $)$. While considerable numbers of spectra were taken at various emission angles, all the photoemission spectra shown in this paper were acquired 
with the photoelectrons collected normal to the surface. The base pressure of the system was maintained at $1 \times 10^{-10}$ Torr. The $\mathrm{Ag}(100)$ and $\mathrm{Cu}(100)$ single crystals were mounted on a cryostat in the analysis chamber with the capability of liquid nitrogen cooling and resistive heating. The temperature was monitored with a K-type (chromel-alumel) thermocouple, and both substrates could be cooled to $150 \mathrm{~K}$. The substrates were cleaned by repeated $\mathrm{Ar}^{+}$ion sputtering and annealing as noted elsewhere. ${ }^{5}$ Ferrocene was sublimed from the solid and admitted into the chamber through a standard leak valve.

The high-resolution electron energy loss (HREELS) spectra were taken in a separate UHV (HREELS) chamber with a base pressure of $8 \times 10^{-11}$ Torr and an LK-2000 angle-resolved electron energy loss spectrometer. An electron beam with an energy of $1.85 \mathrm{eV}$ was incident at an angle of $60^{\circ}$ off the surface normal throughout this work. Spectra were obtained in both specular and off-specular $\left(\Delta \theta=9^{\circ}\right)$ directions following a ferrocene exposure of 2 langmuirs (1langmuir $=1 \times 10^{-6}$ Torr s) on $\mathrm{Ag}(100)$ at $110 \mathrm{~K}$.

The scanning tunneling microscope low-temperature (STM) images of ferrocene on $\mathrm{Cu}(100)$ were collected using an Omicron STM system in a third UHV system. Submonolayer coverages of ferrocene on $\mathrm{Cu}(100)$ were adsorbed at room temperature following a ferrocene exposure of $10^{3}$ langmuirs. Images were acquired using a sample bias of $V_{\text {bias }}=+2 \mathrm{~V}$ with a tunneling current of $I_{\mathrm{t}}=0.5 \mathrm{nA}$ in the traditional current mode.

\section{Theory}

Theoretical calculations were performed to model the ferrocene vibrational modes using the Gaussian-92 ab initio package. ${ }^{14}$ Calculations were undertaken with the standard STO-3G minimal basis set and the extended 3-21G basis set. The initial geometry of ferrocene was determined by assigning the molecule to the $D_{5 d}$ symmetry point group and standard bond lengths. Optimization of this geometry at the self-consistentfield $(\mathrm{SCF})^{15}$ level using the STO-3G basis set resulted in convergence. The SCF-STO-3G optimized geometry was further refined at the SCF-3-21G level and produced a stable minimum retaining the $D_{5 d}$ symmetry. The solutions of the improved force field calculations provide the vibrational frequencies of ferrocene summarized in Table 1. This level of calculation was repeated for deuterated ferrocene (ferrocene$d_{10}$ ), which is also shown in Table 1 . Throughout this article point group representation elements of vibrational modes are denoted by upper case letters and for molecular orbitals by lower case letters.

$\operatorname{Ag}(\mathbf{1 0 0})$. The orientation of ferrocene adsorbed on $\operatorname{Ag}(100)$ at $150 \mathrm{~K}$ as a function of exposure was studied with ARPES (Figures 2 and 3). Panel a shows spectra measured with p-polarized light, and panel $b$ shows spectra acquired with (s $+\mathrm{p}$ )-polarized light. The angle-resolved photoemission spectra, in general, resemble those of the angle-integrated studies reported earlier. ${ }^{5,6}$ These angle-resolved photoemission spectra binding energies are referenced to the $\mathrm{Ag}(100)$ Fermi energy, and because of greater resolution and angular resolution, the binding energies differ slightly from previous work ${ }^{4,5}$ (Table 2).

Upon adsorption of ferrocene, suppression of the $\mathrm{Ag} 4 \mathrm{~d}$ bands and growth of photoemission features at approximately 4.1, 5.4, $7.0,8.9,10.9,13.4$, and $17.0 \mathrm{eV}$ is observed (Figures 2 and 3 ) as summarized in Table 2. There exists a strong similarity between the gas-phase photoemission spectra of ferrocene and condensed ferrocene, ${ }^{5}$ although the molecule to substrate and intermolecular interactions have been observed to shift, split, or broaden the observed energies of the molecular orbitals. On
TABLE 1: Calculated Vibrational Modes of Ferrocene and Deuterated Ferrocene Using the Extended Basis Set (3-21G) As Described in the Text

\begin{tabular}{|c|c|c|c|}
\hline \multicolumn{2}{|c|}{ vibrational losses (meV) } & \multirow[b]{2}{*}{ sym } & \multirow[b]{2}{*}{ vib mode } \\
\hline $\mathrm{Fe}\left(\mathrm{C}_{5} \mathrm{H}_{5}\right)_{2}$ & $\mathrm{Fe}\left(\mathrm{C}_{5} \mathrm{D}_{5}\right)_{2}$ & & \\
\hline 1.4 & 1.3 & $\mathrm{~A}_{1 \mathrm{u}}$ & ring torsion \\
\hline 16.1 & 14.9 & $\mathrm{E}_{1 \mathrm{u}}$ & asymmetric ring tilt \\
\hline 30.5 & 28.9 & $\mathrm{~A}_{1 \mathrm{~g}}$ & metal-ring stretch \\
\hline 40.4 & 36.9 & $\mathrm{E}_{1 \mathrm{~g}}$ & symmetric ring tilt \\
\hline 52.3 & 50.4 & $\mathrm{E}_{1 \mathrm{u}}$ & $\delta\left(\mathrm{M}(\mathrm{Cp})_{2}\right)$ \\
\hline 53.8 & 52.2 & $\mathrm{~A}_{2 \mathrm{u}}$ & $v_{\text {as }}\left(\mathrm{M}(\mathrm{Cp})_{2}\right)$ \\
\hline 79.1 & 70.9 & $\mathrm{E}_{2 \mathrm{u}}$ & $\pi(\mathrm{CH})$ \\
\hline 82.1 & 72.4 & $E_{2 g}$ & $\pi(\mathrm{CH})$ \\
\hline 108.6 & 81.4 & $\mathrm{~A}_{2 \mathrm{u}}$ & $\pi(\mathrm{CH})$ \\
\hline 111.1 & 82.9 & $\mathrm{~A}_{1 \mathrm{~g}}$ & $\pi(\mathrm{CH})$ \\
\hline 111.7 & 87.4 & $\mathrm{E}_{1 \mathrm{~g}}$ & $\pi(\mathrm{CC})$ \\
\hline 115.8 & 90.4 & $\mathrm{E}_{1 \mathrm{u}}$ & $\pi(\mathrm{CH})$ \\
\hline 119.7 & 97.8 & $\mathrm{E}_{2 \mathrm{u}}$ & $\pi(\mathrm{CH})$ \\
\hline 119.9 & 101.4 & $\mathrm{E}_{2 \mathrm{~g}}$ & $\delta(\mathrm{CC})$ \\
\hline 124.1 & 102.6 & $\mathrm{E}_{2 \mathrm{u}}$ & $\pi(\mathrm{CC})$ \\
\hline 126.5 & 102.8 & $\mathrm{E}_{2 \mathrm{~g}}$ & $\pi(\mathrm{CH})$ \\
\hline 136.1 & 105.7 & $\mathrm{E}_{1 \mathrm{~g}}$ & $\pi(\mathrm{CC})$ \\
\hline 136.9 & 106.3 & $\mathrm{E}_{1 \mathrm{u}}$ & $\pi(\mathrm{CH})$ \\
\hline 145.5 & 119.9 & $\mathrm{E}_{2 \mathrm{u}}$ & $\pi(\mathrm{CC})$ \\
\hline 146.6 & 120.3 & $\mathrm{E}_{2 \mathrm{~g}}$ & $\delta(\mathrm{CH})$ \\
\hline 148.4 & 140.8 & $\mathrm{~A}_{2 \mathrm{u}}$ & $\delta(\mathrm{CH})$ \\
\hline 148.9 & 141.2 & $\mathrm{~A}_{1 \mathrm{~g}}$ & $\delta(\mathrm{CH})$ \\
\hline 177.2 & 139.01 & $\mathrm{~A}_{2 \mathrm{~g}}$ & ring breathing \\
\hline 177.3 & 139.05 & $\mathrm{~A}_{1 \mathrm{u}}$ & $v(\mathrm{CH})$ \\
\hline 182.8 & 175.3 & $\mathrm{E}_{2 \mathrm{u}}$ & $\pi(\mathrm{CH})$ \\
\hline 185.8 & 176.9 & $\mathrm{E}_{2 \mathrm{~g}}$ & $\delta(\mathrm{CH})$ \\
\hline 195.8 & 179.0 & $\mathrm{E}_{1 \mathrm{~g}}$ & $\delta(\mathrm{CH})$ \\
\hline 196.0 & 177.4 & $\mathrm{E}_{1 \mathrm{u}}$ & $\pi(\mathrm{CH})$ \\
\hline 425.4 & 314.5 & $\mathrm{E}_{2 \mathrm{u}}$ & $\pi(\mathrm{CH})$ \\
\hline 425.5 & 314.7 & $\mathrm{E}_{2 \mathrm{~g}}$ & $\delta(\mathrm{CH})$ \\
\hline 427.5 & 316.7 & $\mathrm{E}_{1 \mathrm{~g}}$ & $\pi(\mathrm{CH})$ \\
\hline 427.6 & 316.8 & $\mathrm{E}_{1 \mathrm{u}}$ & $\pi(\mathrm{CH})$ \\
\hline 429.7 & 320.21 & $\mathrm{~A}_{2 \mathrm{u}}$ & $\delta(\mathrm{CH})$ \\
\hline 429.8 & 320.22 & $\mathrm{~A}_{1 \mathrm{~g}}$ & $\delta(\mathrm{CH})$ \\
\hline
\end{tabular}

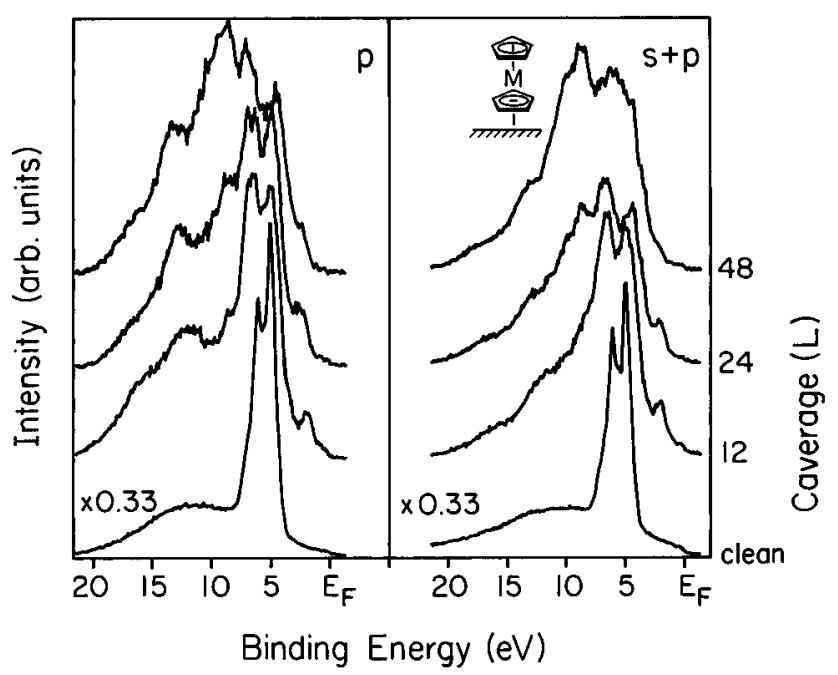

Figure 2. Coverage-dependent angle-resolved photoemission spectra of ferrocene on $\operatorname{Ag}(100)$ at $150 \mathrm{~K}$ using a $50 \mathrm{eV}$ incident beam with normal emission. The spectra in panel (a) were measured using p-polarized light. The spectra in panel $\mathrm{b}$ were measured using $(\mathrm{s}+$ p)-polarized light.

the basis of theoretical calculations of the ground-state molecular orbitals of ferrocene $\mathrm{e}^{16-22}$ as well as gas-phase photoemission and ionization potential studies, ${ }^{23-27}$ we can assign the adsorbed ferrocene-induced photoemission features to the molecular orbitals of ferrocene (Table 2, Figures 2 and 3). The features at 5.4 and $4.1 \mathrm{eV}$ arise from the ferrocene $8 \mathrm{a}_{1 \mathrm{~g}}$ and $4 \mathrm{e}_{2 \mathrm{~g}}$ 
TABLE 2: Molecular Orbital Binding Energies (eV) for Ferrocene ${ }^{a}$

\begin{tabular}{|c|c|c|c|c|}
\hline molecular orbitals & theory & gas phase & $\operatorname{Ag}(100)$ & $\mathrm{Cu}(100)$ \\
\hline $8 \mathrm{a}_{1 \mathrm{~g}}$ & $\begin{array}{c}7.46^{16} \\
10.1^{17} \\
7.9^{18} \\
6.45^{19} \\
6.7^{20} \\
7.6^{21} \\
6.6^{22}\end{array}$ & $\begin{array}{l}6.88^{23} \\
6.85^{24} \\
6.9^{25} \\
6.86^{26} \\
6.86^{27}\end{array}$ & 5.4 & not resolved from $4 \mathrm{e}_{2 \mathrm{~g}}$ \\
\hline $4 e_{2 g}$ & $\begin{array}{l}5.6^{16} \\
8.3^{17} \\
8.5^{18} \\
6.6^{19} \\
6.7^{20} \\
6.7^{22}\end{array}$ & $\begin{array}{l}7.23^{23} \\
7.21^{24} \\
7.23^{25} \\
7.21^{27}\end{array}$ & $\begin{array}{l}4.1 \\
4.6^{5,6}\end{array}$ & 4.2 \\
\hline $6 e_{1 u}$ & $\begin{array}{c}8.85^{16} \\
11.1^{17} \\
9.3^{18} \\
8.53^{19} \\
8.6^{20} \\
12.6^{21} \\
8.6^{22}\end{array}$ & $\begin{array}{l}8.72^{23} \\
8.72^{24} \\
8.72^{25} \\
8.77^{27}\end{array}$ & $\begin{array}{l}7.0 \\
7.3^{5,6}\end{array}$ & 7.1 \\
\hline $4 e_{1 g}$ & $\begin{array}{c}8.79^{16} \\
11.2^{17} \\
9.7^{18} \\
7.96^{19} \\
8.1^{20} \\
14.58^{21} \\
7.2^{22}\end{array}$ & $\begin{array}{l}9.38^{23} \\
9.17^{24} \\
9.38^{25} \\
9.28^{27}\end{array}$ & not resolved from $6 \mathrm{e}_{1 \mathrm{u}}$ & not resolved from $6 \mathrm{e}_{1 \mathrm{u}}$ \\
\hline $6 \mathrm{a}_{2 \mathrm{u}}$ & $\begin{array}{l}13.03^{16} \\
15.5^{17} \\
11.7^{18}\end{array}$ & $\begin{array}{l}12.3^{23} \\
12.2^{25} \\
12.2^{27}\end{array}$ & $\begin{array}{l}8.9 \\
9.3^{5,6}\end{array}$ & 8.9 \\
\hline $3 e_{2 u}, 3 e_{2 g}, 3 e_{1 g}, 5 e_{1 u}$ and $7 a_{1 g}$ & $\begin{array}{l}13.6^{16} \\
11.6^{18}\end{array}$ & $\begin{array}{l}13.0^{23} \\
13.46^{23} \\
13.6^{25} \\
13.3^{27}\end{array}$ & $\begin{array}{l}10.9 \\
11.9^{5,6}\end{array}$ & not resolved from $6 \mathrm{a}_{2 \mathrm{u}}$ \\
\hline $5 \mathrm{a}_{2 \mathrm{u}}, 6 \mathrm{a}_{1 \mathrm{~g}}, 2 \mathrm{e}_{2 \mathrm{u}}$, and $2 \mathrm{e}_{1 \mathrm{~g}}$ & & $\begin{array}{l}16.5^{23} \\
16.4^{25} \\
16.6^{27} \\
19.5^{27}\end{array}$ & $\begin{array}{l}13.4 \\
14.1^{5,6} \\
\\
17.0 \\
18^{5,6}\end{array}$ & $\begin{array}{l}13.1 \\
16.3\end{array}$ \\
\hline
\end{tabular}

${ }^{a}$ The binding energies for theory and gas-phase experimental measurements are relative to the vacuum level. Those for the condensed phase are taken from ref 4 and referenced to the Fermi level.

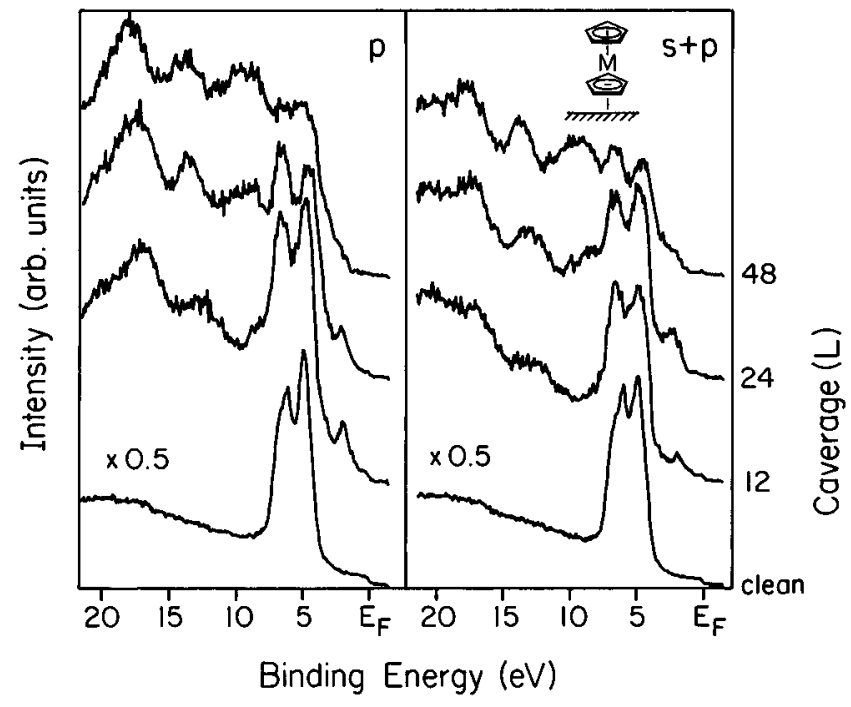

Figure 3. Coverage-dependent angle-resolved photoemission spectra of ferrocene on $\mathrm{Ag}(100)$ at $150 \mathrm{~K}$ using a $60 \mathrm{eV}$ incident beam with normal emission. The spectra in panel a were measured using p-polarized light. The spectra in panel $b$ were measured using $(\mathrm{s}+$ p)-polarized light.

molecular orbitals, respectively. The $6 \mathrm{e}_{1 \mathrm{u}}$ and $4 \mathrm{e}_{1 \mathrm{~g}}$ molecular orbitals result in the $7.0 \mathrm{eV}$ feature. The feature at $8.9 \mathrm{eV}$ binding energy (the $6 \mathrm{a}_{2 \mathrm{u}}$ molecular orbital) and the prominent shoulder at $10.9 \mathrm{eV}$ binding energies have contributions from a combination of molecular orbitals $\left(3 \mathrm{e}_{2 \mathrm{u}}, 3 \mathrm{e}_{2 \mathrm{~g}}, 3 \mathrm{e}_{1 \mathrm{~g}}, 5 \mathrm{e}_{1 \mathrm{u}}\right.$, and $\left.7 \mathrm{a}_{2 \mathrm{~g}}\right)$ as is the case for the $13.4 \mathrm{eV}$ feature $\left(5 \mathrm{a}_{2 \mathrm{u}}, 6 \mathrm{a}_{1 \mathrm{~g}}, 2 \mathrm{e}_{2 \mathrm{u}}\right.$, and $2 \mathrm{e}_{1 \mathrm{~g}}$ ). The feature at $17.0 \mathrm{eV}$ is primarily of carbon $2 \mathrm{~s}$ in origin. The peak at $2.2 \mathrm{eV}$ has not been uniquely identified but may result from the interfacial reaction between ferrocene and the surface (or cyclopentadienyl fragments), since it is well-resolved at low coverages.

The $5-6 \mathrm{eV}$ feature is assigned to the $8 \mathrm{a}_{1 \mathrm{~g}}$ molecular orbital on the basis that this feature shows the same light polarization dependence as the $17.0 \mathrm{eV}$ feature. The distinct separation of the $8 \mathrm{a}_{1 \mathrm{~g}}$ from the $4 \mathrm{e}_{2 \mathrm{~g}}$ molecular orbital indicates that the $8 \mathrm{a}_{1 \mathrm{~g}}$ is a bonding orbital and no longer the highest occupied molecular orbital.

In spectra obtained using $(s+p)$-polarized light (shown in Figures $2 \mathrm{~b}$ and $3 \mathrm{~b}$ ), relative peak intensities corresponding to various molecular orbitals change significantly when compared to those using p-polarized light (Figures $2 \mathrm{a}$ and $3 \mathrm{a}$ ). The peaks at 5.4, 13.4, and $17 \mathrm{eV}$ decrease in intensity compared to the p-polarized spectra, while the $7,8.9,10.9$, and $13.1 \mathrm{eV}$ features remain unchanged or increased. These latter features are primarily of $e_{1}$ and $e_{2}$ symmetry, while the 5.4, 13.4, and 17.0 $\mathrm{eV}$ features contain substantial $\mathrm{a}_{1}$ character. This enhancement of the fully symmetric molecular orbitals in p-polarized light is strongly indicative of a molecular orientation along the surface normal.

Figure 4 shows the HREELS spectra of ferrocene on Ag(100) at $110 \mathrm{~K}$. In the specular direction, the spectra exhibit 


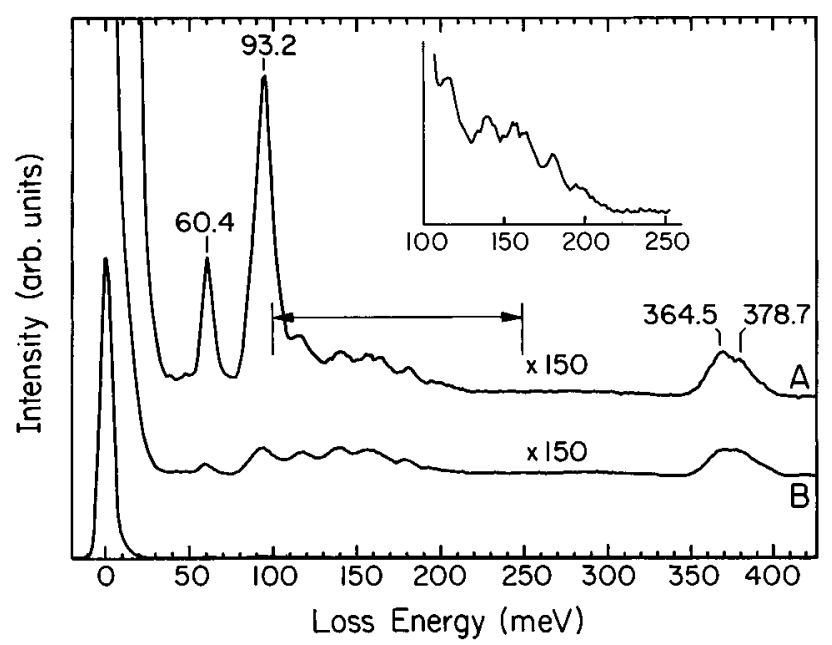

Figure 4. Electron energy loss spectra for ferrocene adsorbed on $\mathrm{Ag}$ (100) at $110 \mathrm{~K}$. The spectra were taken following 2 langmuir exposure. Both the specular (A) and off-specular $\left(\mathrm{B}, \Delta \theta=9^{\circ}\right)$ spectra are shown with the same scale but magnified by 150 as compared to the specular elastic peak. The inset shows features in the range from 100 to 250 $\mathrm{meV}$. The intensities of the two dipole-active modes $v_{\text {as }}\left(\mathrm{M}(\mathrm{Cp})_{2}\right)$ and $\pi(\mathrm{CH})$, at 60.4 and $93.2 \mathrm{meV}$, respectively, are greatly suppressed in the off-specular geometry while the peaks at 364.5 and $378.7 \mathrm{meV}$ are not.

Intro-ring $\left(\mathrm{C}_{5} \mathrm{H}_{5}\right)$ modes:
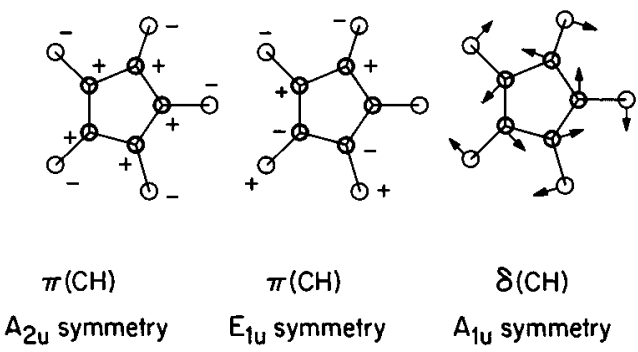

Skeletal (ring-metal) mode:

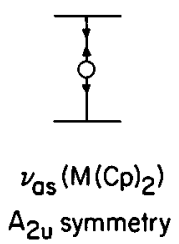

Figure 5. Normal modes of vibration for the loss peaks in the HREELS spectrum of ferrocene.

strong peaks located at $60.4,93.2,364.5$, and $378.7 \mathrm{meV}$ with a number of weaker loss features in the range $100-200 \mathrm{meV}$. The spectrum acquired in the off-specular geometry is characterized by the suppression of the 60.4 and $93.2 \mathrm{meV}$ features while all the other peaks remain largely unchanged. Clearly, the 60.4 and $93.2 \mathrm{meV}$ losses are strongly dipole-active modes.

We adopted the $D_{5 d}$ structure in our model calculations and for assignment of the vibrational losses. The intra-ring (Cp) modes follow vibrations consistent with the $D_{5 h}$ symmetry group, and skeletal modes follow vibrations consistent with the $D_{5 d}$ symmetry group. The symmetry and schematic representation of the important vibrational modes are indicated in Figure 5 .

On the basis of our calculations, we assign the vibrational loss peak at $60.4 \mathrm{meV}$ to the antisymmetric skeletal vibrational mode of the metal $(\mathrm{M})$ atom and cyclopentadienyl rings $(\mathrm{Cp})$,
TABLE 3: Vibrational Modes of the HREEL Spectrum of Ferrocene $^{a}$

\begin{tabular}{ccccc}
\hline $\begin{array}{c}\text { calcd energies } \\
(\mathrm{meV})\end{array}$ & $\mathrm{sym}$ & vib mode & $\begin{array}{c}\text { obsd IR } \\
(\mathrm{meV})\end{array}$ & $\begin{array}{c}\text { HREELS } \\
(\mathrm{meV})\end{array}$ \\
\hline $53.8(31.3)$ & $\mathrm{A}_{2 \mathrm{u}}$ & $v_{\mathrm{as}}\left(\mathrm{M}(\mathrm{Cp})_{2}\right)$ & $\begin{array}{c}59.3^{c} \\
60^{f}\end{array}$ & $\begin{array}{l}60.4^{b} \\
68^{g}\end{array}$ \\
& & & $96.1^{c}$ & $93.2^{b}$ \\
$108.6(117.3)$ & $\mathrm{A}_{2 \mathrm{u}}$ & $\pi(\mathrm{CH})$ & $102^{f}$ & $101^{g}$ \\
& & & $118.2^{d}$ & $115.0^{b}$ \\
$119.7(114.9)$ & $\mathrm{E}_{2 \mathrm{u}}$ & $\pi(\mathrm{CH})$ & $137.4^{c}$ & $140.0^{b}$ \\
$136.9(145.5)$ & $\mathrm{E}_{1 \mathrm{u}}$ & $\pi(\mathrm{CH})$ & $138^{f}$ & $135^{g}$ \\
& & & $155.5^{e}$ & $155.0^{b}$ \\
$148.4(158.8)$ & $\mathrm{A}_{2 \mathrm{u}}$ & $\delta(\mathrm{CH})$ & $183.0^{d}$ & $180.0^{b}$ \\
$182.8(200.3)$ & $\mathrm{E}_{2 \mathrm{u}}$ & $\pi(\mathrm{CH})$ & $176^{f}$ & $170^{g}$ \\
& & & $200.8^{c}$ & $195.0^{b}$ \\
$196.0(211.6)$ & $\mathrm{E}_{1 \mathrm{u}}$ & $\pi(\mathrm{CH})$ & $387^{f}$ & $378.5^{b}$ \\
& & & & $390^{g}$ \\
$429.7(471.0)$ & $\mathrm{A}_{2 \mathrm{u}}$ & $\delta(\mathrm{CH})$ & & $364.5^{b}$ \\
& & & & $353^{g}$
\end{tabular}

${ }^{a}$ Calculated vibrational modes of ferrocene under 3-21G (STO-3G) are listed in meV. Calculations show better agreement with the extended basis set: see text. ${ }^{b}$ This work ${ }^{c}$ Taken from ref $28{ }^{d}$ Taken from ref $29 .{ }^{e}$ Taken from ref $30 .{ }^{f}$ Taken from ref $31 .{ }^{g}$ Taken from ref 25 .

$v_{\text {as }}\left(\mathrm{M}(\mathrm{Cp})_{2}\right)$, of $\mathrm{A}_{2 \mathrm{u}}$ symmetry. Similarly, the peak at $93.2 \mathrm{meV}$ is assigned as the out-of-plane vibrational mode of the $\mathrm{C}-\mathrm{H}$ bond, $\pi(\mathrm{CH})$, which is also of $\mathrm{A}_{2 u}$ symmetry. A weak $\mathrm{A}_{2 u}$ symmetry dipole-active mode is observed at $364.5 \mathrm{meV}$. Both theory and experiment are in very good agreement, as seen in Table 3 .

Both specular and off-specular spectra (Figure 4) show weak losses in the range from 100 to $200 \mathrm{meV}$, which remain largely the same in intensity in both geometries. This suggests that these peaks correspond to impact (nondipole) scattering modes. The selection rules for HREEL spectroscopy favor $E_{1 u}$ and $E_{2 u}$ symmetries for nondipole-active modes, and we have made our assignments accordingly except for one $\mathrm{A}_{2 \mathrm{u}}$ dipole mode. The experimental losses are in-plane and out-of-plane bending mode vibrations of the $\mathrm{C}-\mathrm{H}$ bond as seen in Table 3 and are in good agreement with theory.

Our calculated vibrational energies at 53.8, 108.6, and 196.0 $\mathrm{meV}$ are consistent with the vibrational loss peaks at 60.4, 93.2, and $195.0 \mathrm{meV}$, respectively. These values also agree with the IR data ${ }^{28}$ for gaseous ferrocene at 59.3, 96.1, and $200.8 \mathrm{meV}$, respectively. For cyclopentane $\left(\mathrm{C}_{5} \mathrm{H}_{10}\right)$ in crystal form, the IR data $^{29}$ find features at 118.2 and $183 \mathrm{meV}$. These agree with our calculated values at 119.7 and $182.8 \mathrm{meV}$ and the HREELS data as indicated in Table 3. We therefore assign these losses in our HREELS data to $\mathrm{C}-\mathrm{H}$ modes. Our calculations indicate that these two peaks correspond to $\pi(\mathrm{CH})$ modes. A peak is observed at $155.5 \mathrm{meV}$ in the IR data for crystalline ferrocene. ${ }^{30}$ This agrees with the calculated value at $148.4 \mathrm{meV}$ and the HREELS vibrational loss peak at $155 \mathrm{meV}$ and, in principle, should be a dipole-acitve mode.

The peaks at 364.5 and $378.7 \mathrm{meV}$ should correspond to a dipole-active mode and an impact scattering mode, respectively. The $364.5 \mathrm{meV}$ mode is indeed enhanced in the specular geometry while the other loss feature remains largely the same in intensity in both geometries. These two modes can be assigned as a $\delta(\mathrm{CH})$ mode of $\mathrm{A}_{2 \mathrm{u}}$ symmetry and a $\pi(\mathrm{CH})$ vibrational mode of $\mathrm{E}_{1 \mathrm{u}}$ symmetry. In the infrared data of ferrocene in solution, ${ }^{31}$ an absorption at $387 \mathrm{meV}$, has been observed, while these losses have also been observed in highresolution photoemission ${ }^{25}$ at 353 and $390 \mathrm{meV}$ respectively. We note that the calculated values and the HREELS loss 
energies of these peaks are not in good agreement. It is difficult to explain the vibrational losses at 242,278 , and $316 \mathrm{meV}$ observed in the gas-phase photoemission ${ }^{25}$ as anything except as overtones: these losses have no calculated counterpart.

In addition to the vibrational modes for the HREELS peaks, we can assign other observed IR and Raman modes for ferrocene from the literature. The symmetries $A_{1 g}, A_{2 g}, E_{1 g}$, and $E_{2 g}$ correspond to Raman-active modes while $\mathrm{E}_{2 \mathrm{u}}$ corresponds to inactive IR modes. Overall, we have been able to assign modes of $A_{1 g}, A_{2 g}, E_{1 g}, E_{2 g}$, and $E_{2 u}$ symmetries.

The energy range from 15 to $55 \mathrm{meV}$ is dominated by skeletal (metal-ring) modes. The two asymmetric ring tilt modes at 16.1 and $52.3 \mathrm{meV}$ have $\mathrm{E}_{1 \mathrm{u}}$ symmetry. The $16.1 \mathrm{meV}$ mode agrees with solution IR data ${ }^{31}$ for ferrocene at $21 \mathrm{meV}$, and the $52.3 \mathrm{meV}$ mode agrees with IR data $^{28}$ for ruthenocene in solution. The metal-ring stretch mode at $30.5 \mathrm{meV}$ is of $\mathrm{A}_{1 \mathrm{~g}}$ symmetry and agrees with Raman data ${ }^{28}$ for ferrocene- $d_{10}$ in solution. The symmetric ring tilt mode at $40.4 \mathrm{meV}$ is of $\mathrm{E}_{1 \mathrm{~g}}$ symmetry and agrees with Raman data ${ }^{28}$ for ferrocene in solution. The observed gas-phase electron energy loss at 35 $\mathrm{meV}$, in high-resolution photoemission, ${ }^{25}$ may be assigned to either $\mathrm{A}_{1 \mathrm{~g}}$ or $\mathrm{E}_{1 \mathrm{~g}}$ vibrational modes.

There is a ring breathing mode of totally symmetric representation, $\mathrm{A}_{2 \mathrm{~g}}$, at $177.2 \mathrm{meV}$. This agrees with Raman data ${ }^{29}$ for cyclopentane in crystal form. The two out-of-plane bending modes at 111.1 and $111.7 \mathrm{meV}$, of $\mathrm{A}_{1 \mathrm{~g}}$ and $\mathrm{E}_{1 \mathrm{~g}}$ symmetries, also agree with Raman data ${ }^{29}$ for cyclopentane in liquid and crystal forms, respectively. The in-plane $\mathrm{C}-\mathrm{H}$ bending modes at 148.4 and $185.8 \mathrm{meV}$, of $\mathrm{A}_{2 \mathrm{u}}$ and $\mathrm{E}_{2 \mathrm{~g}}$ symmetries, respectively, agree with Raman data ${ }^{29}$ for cyclopentane in crystal form. The out-of-plane $\mathrm{C}-\mathrm{C}$ bending mode at $136.1 \mathrm{meV}$ agrees with Raman data $^{29}$ for cyclopentane- $d_{10}$ in liquid form. The calculated losses at energies 146.6 and $195.8 \mathrm{meV}$ are attributed to the in-plane $\mathrm{C}-\mathrm{H}$ bending modes of $\mathrm{E}_{2 \mathrm{~g}}$ symmetry which agree with solution Raman data ${ }^{28}$ for ferrocene.

Based on our calculations, HREELS $\mathrm{E}_{1 \mathrm{u}} \pi(\mathrm{CH})$ losses in the vicinity of 16.1 and $115.8 \mathrm{meV}$ and an $\mathrm{E}_{2 \mathrm{u}}$ loss at $124.1 \mathrm{meV}$ as well as an $\mathrm{E}_{1 \mathrm{u}} \delta \mathrm{M}(\mathrm{Cp})_{2}$ mode at $52.3 \mathrm{meV}$ are expected. Recent high-resolution HREELS studies of condensed ferrocene $^{32}$ have observed these additional modes at 22.6, 100, 123.8 , and $46.3 \mathrm{meV}$, respectively.

The general softening of the modes with deuteration that we have calculated has been observed. In particular, the $\mathrm{A}_{2 \mathrm{u}}$ mode calculated for $\mathrm{Fe}\left(\mathrm{C}_{5} \mathrm{D}_{5}\right)_{2}$ at $81.4 \mathrm{meV}\left(108.6 \mathrm{meV}\right.$ for $\left.\mathrm{Fe}\left(\mathrm{C}_{5} \mathrm{H}_{5}\right)_{2}\right)$ is observed at $79 \mathrm{meV}$ as opposed to $102 \mathrm{meV}$ for $\mathrm{Fe}\left(\mathrm{C}_{5} \mathrm{H}_{5}\right)_{2}$ in the same solution. ${ }^{31}$

$\mathbf{C u}(\mathbf{1 0 0})$. Figure 6 shows ARPES spectra for ferrocene adsorbed on $\mathrm{Cu}(100)$ as a function of exposure. Panel a shows spectra measured with p-polarized light, and panel b shows spectra measured with $(\mathrm{s}+\mathrm{p})$-polarized light.

Upon adsorption of ferrocene at $150 \mathrm{~K}$, there is suppression of the $\mathrm{Cu} 3 \mathrm{~d}$ bands and an increase of photoemission features at binding energies of approximately 4.2, 7.1, 8.9, 13.1, and $16.3 \mathrm{eV}$ as seen in Figure 6 and summarized in Table 2. The spectra for ferrocene on $\mathrm{Cu}(100)$ are qualitatively similar to those obtained on the $\operatorname{Ag}(100)$ surface. Again, on the basis of theoretical calculations of the ground-state molecular orbitals of ferrocene $\mathrm{e}^{16-22}$ and gas-phase photoemission and ionization potential studies, ${ }^{23-27}$ we can assign these photoemission features of the adsorbed species (Table 2, Figure 5). The ferrocene $8 \mathrm{a}_{1 \mathrm{~g}}$ and $4 \mathrm{e}_{2 \mathrm{~g}}$ molecular orbitals induce the $4.2 \mathrm{eV}$ feature that overlaps with the $\mathrm{Cu} 3 \mathrm{~d}$ bands. The $6 \mathrm{e}_{1 \mathrm{u}}$ and $4 \mathrm{e}_{1 \mathrm{~g}}$ molecular orbitals result in the $7.1 \mathrm{eV}$ feature. The prominent feature at a binding energy of $8.7 \mathrm{eV}$ binding energy (the $6 \mathrm{a}_{2 \mathrm{u}}$ molecular orbital) is no longer distinct from the combination

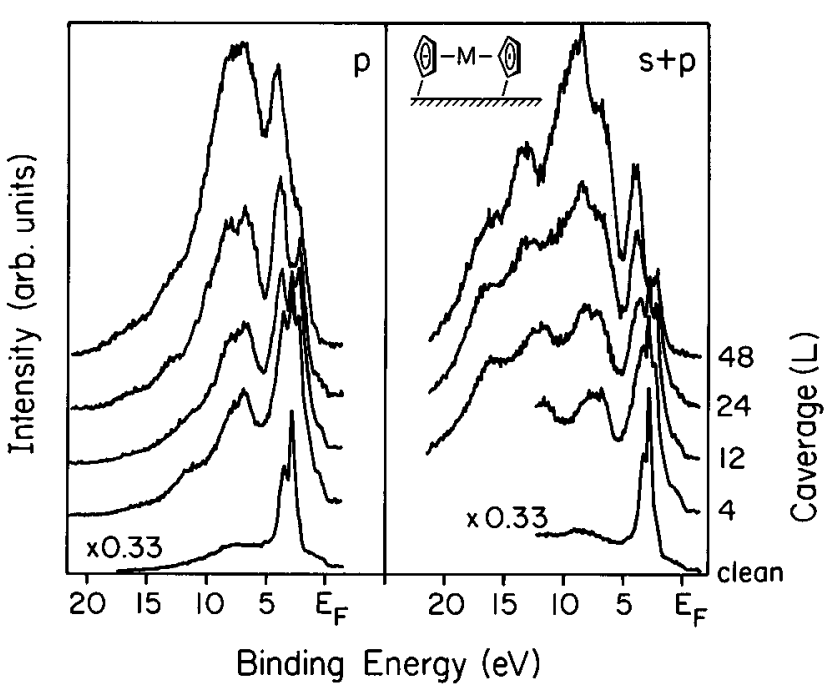

Figure 6. Coverage-dependent angle-resolved photoemission spectra of ferrocene on $\mathrm{Cu}(100)$ at $150 \mathrm{~K}$ using a $50 \mathrm{eV}$ incident beam with all the photoelectrons collected along the surface normal. The spectra in panel a were measured using p-polarized light. The spectra in panel $\mathrm{b}$ were measured using $(\mathrm{s}+\mathrm{p})$-polarized light.

of molecular orbitals $\left(3 \mathrm{e}_{2 \mathrm{u}}, 3 \mathrm{e}_{2 \mathrm{~g}}, 3 \mathrm{e}_{1 \mathrm{~g}}, 5 \mathrm{e}_{1 \mathrm{u}}\right.$, and $\left.7 \mathrm{a}_{2 \mathrm{~g}}\right)$ that appear at higher binding energies. The $13.1 \mathrm{eV}$ feature is also a combination of several molecular orbitals $\left(5 \mathrm{a}_{2 \mathrm{u}}, 6 \mathrm{a}_{1 \mathrm{~g}}, 2 \mathrm{e}_{2 \mathrm{u}}\right.$, and $2 \mathrm{e}_{1 \mathrm{~g}}$ ).

For the spectra recorded with $(s+p)$-polarized light (Figure $6 \mathrm{~b}$ ), relative intensities of the molecular orbitals again change significantly from p-polarized light (Figure 6a), but in a slightly different manner to those of ferrocene on $\mathrm{Ag}(100)$. The peaks at $4.2,8.9,13.1$, and $16.3 \mathrm{eV}$ now increase (instead of decrease or remain the same) in intensity compared to the p-polarized spectra while the feature at $7.1 \mathrm{eV}$ remains the same or decreases. The change in the intensity of the 8.9, 13.1, and $16.3 \mathrm{eV}$ features with light polarization is opposite to the case for ferrocene on $\operatorname{Ag}(100)$. Since some features with substantial $\mathrm{a}_{1}$ character increase with $(\mathrm{s}+\mathrm{p})$-polarized light, this suggests that the molecular axis of the ferrocene is not placed perpendicular to the surface. Rather, the photoemission is consistent with a canted or "flat" molecular configuration; in other words, the ferrocene is bonded with the molecular axis tilted away from the surface normal-possibly even with the molecular axis parallel with the surface. This does not mean that there is no preferential orientation-the existence of light incident angle dependence does argue for a preferential orientation, but the specific orientation cannot be easily assigned on the basis of the angle-resolved photoemission results alone.

The scanning tunneling microscope images of ferrocene adsorbed on $\mathrm{Cu}(100)$ at room temperature are shown in Figure 7. The three lobes imaged in the STM are very indicative of a molecular ferrocene species oriented with the molecular axis parallel with the surface. The images indicate that the molecular axis is, in fact, along the $\langle 110\rangle$ direction. This molecular orientation is quite consistent with the angle resolved photoemission results.

No such ferrocene species could be observed on $\operatorname{Ag}(100)$ using scanning tunneling microscopy following large exposures of ferrocene to $\operatorname{Ag}(100)$ at temperatures as low as $230 \mathrm{~K}$. The fact that such room-temperature adsorption is observable only for ferrocene on $\mathrm{Cu}(100)$ and not $\mathrm{Ag}(100)$ suggests that this ferrocene species is a partially dehydrogenated ferrocene. This would account for the higher effective desorption temperature than most of the molecularly adsorbed ferrocene on $\mathrm{Cu}(100)$ (or $\operatorname{Ag}(100)$ for that matter). 

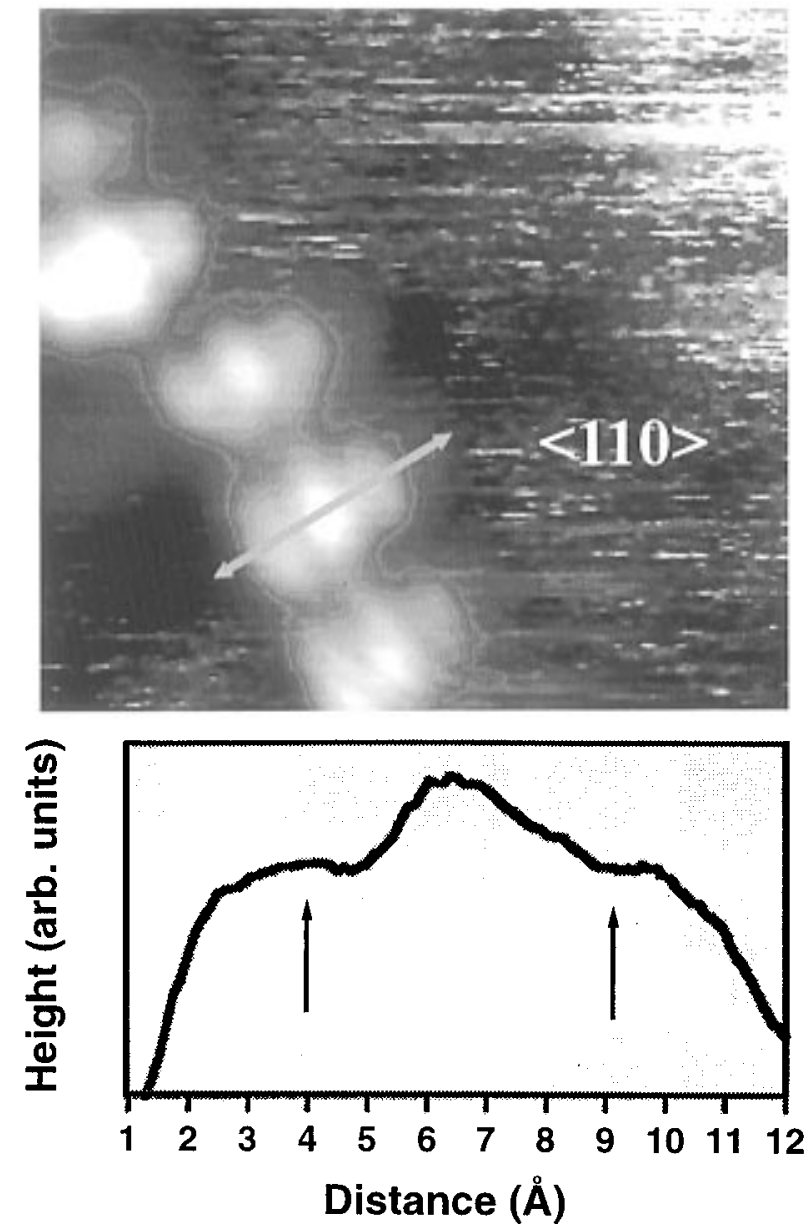

$\bigcirc$

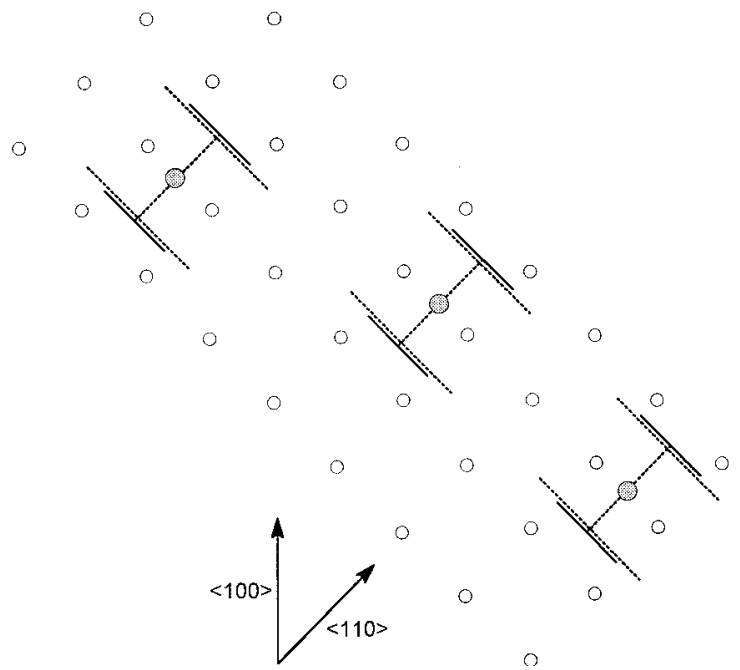

Figure 7. A constant-current STM image ( 4 by $4 \mathrm{~nm}$ ) of ferrocene molecules adsorbed on $\mathrm{Cu}(100)$ following adsorption at room temperature. The trace through one of the adsorbed ferrocene molecules is also shown along the $\langle 110\rangle$ direction. The relative orientation of the molecule on the $\mathrm{Cu}(100)$ surface is indicated schematically. (The solid line represents the 1,2-hydrogen vector, and the dotted line represents the 1,3-hydrogen vector.)

\section{Discussion}

The vibrational modes for most of the peaks in the HREEL spectra of ferrocene are reasonably modeled by our calculations based on the extended basis set (3-21G) calculations. The limited basis set (STO-3G) is less successful in modeling ferrocene. The infrared data and Raman data available in the

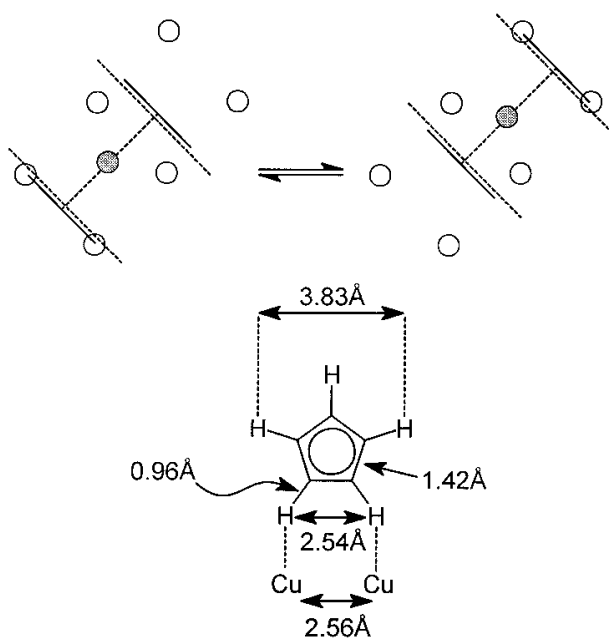

Figure 8. Schematic representation of the possible bonding configurations of ferrocene on $\mathrm{Cu}(100)$ consistent with the angle-resolved photoemission results following adsorption at $150 \mathrm{~K}$ and the STM images shown in Figure 7.

literature support our assignments of vibrational modes of HREELS and the premise that ferrocene is a weakly bound adsorbate on $\operatorname{Ag}(100) .{ }^{5}$ We find that adsorption of ferrocene does not result in a large perturbation of the vibrational modes. Nevertheless, the peaks found at high frequency indicate that significant improvements in the method of calculations are required. We anticipate that the use of an anharmonic force field may enhance the accuracy of the results and would allow us to better model the vibrational modes for all the peaks in the HREEL spectrum of ferrocene. Anharmonic corrections would lead to a softening of the modes, as compared to the pure harmonic potential, consistent with our data. We are currently exploring these inconsistencies through the use of ferrocene- $d_{10}$ as a prelude to more advanced theoretical studies.

We have postulated in a previous paper $^{5}$ that molecular ferrocene is bound to $\operatorname{Ag}(100)$ through the plane of the cyclopentadienyl ring and resulting in a bonding orientation that places the molecular axis along the surface normal. The model calculations when compared to the HREELS data and the polarization dependence of the angle-resolved photoemission data both strongly support this contention. Bonding to the substrate occurs via $\mathrm{a}_{1}$ orbitals as indicated by the perturbation of the $8 \mathrm{a}_{1 \mathrm{~g}}$ and $6 \mathrm{a}_{1 \mathrm{~g}}$ orbitals.

For $\mathrm{Cu}(100)$, it is very clear that a different preferential bonding orientation is adopted despite the similar chemistry of copper and silver, and we are currently undertaking experiments to elucidate these differences. We note, however, that the calculated separation between two adjacent hydrogens of an ideal cyclopentadienyl ligand $(2.54 \AA)$ is closely matched to the $\mathrm{Cu}-\mathrm{Cu}$ separation of $2.56 \AA$ compared to the corresponding $\mathrm{Ag}-\mathrm{Ag}$ separation of $2.89 \AA$, as seen in Figure 1. A strong chelating interaction by two adjacent cyclopentadienyl hydrogens to the copper surface would therefore seem possible, as seen in Figure 8. Such an interaction would not require the molecular axis of the ferrocene to be perpendicular to the surface, in agreement with the spectroscopic results for $\mathrm{Cu}(100)$.

Although extraction of intermolecular distances from STM data is difficult, the observed distance between the midpoints of the external features (ca. 5.5 $\AA$, as seen in Figure 7) is inconsistent with the separation between the cyclopentadienyl rings of ferrocene (3.32 $\AA$ ), even if the molecular axis of the ferrocene was parallel to the surface. Adoption of this configuration by the ferrocene would enable the hydrogen atoms on 
the unattached ring to be available for binding. However, due to the lattice separation, there are no copper atoms in an appropriate position for this to take place, as indicated by the schematic diagram in Figure 8. Nevertheless, a second energy minima is readily obtained by lengthening and ultimately cleaving the copper-hydrogen interaction of one ring by displacement of the ferrocene molecule along its axis by some $2 \AA$ and concomitant generation of a second copper hydrogen chelating interaction through the cyclopentadienyl protons of the second ring. Since the energy minima are equal in energy and the barrier between them is low, the molecule will shuttle rapidly between the two paired sites, as indicated by Figure 8 . Movement to adjacent paired sites is also possible; however, the barrier to this is presumably sufficiently large to permit observation of the STM images. This model provides an attractive explanation of the elongated features in the STM images of ferrocene on $\mathrm{Cu}(100)$ which arise from a siteaveraged environment which increases the apparent length of the ferrocene molecule by some $2 \AA$.

We have been unsuccessful in obtaining STM data for ferrocene bound to $\operatorname{Ag}(100)$. Ferrocene is bound to the surface of $\operatorname{Ag}(100)$ through the $\pi$-system of the cyclopentadienyl ring with the molecular axis perpendicular to the surface. As a result, increased mobility of ferrocene over the surface of the silver when compared to the differing bonding orientation on $\mathrm{Cu}(100)$ is not unexpected and may be the origin of a lack of data.

It must be realized that the experiments detailed in this paper cannot detect dehydrogenation of the cyclopentadienyl ligands, and while the $8 \mathrm{a}_{1 \mathrm{~g}}$ and $6 \mathrm{a}_{1 \mathrm{~g}}$ molecular orbitals for ferrocene on $\mathrm{Cu}(100)$ have smaller binding energies than is the case for ferrocene on $\mathrm{Ag}(100)$, the bonding mechanism cannot be elucidated from our photoemission results. It is important to be aware that dehydrogenation can change bonding configurations; for example, $o$-xylene bonding orientation to the surface is dominated by the partial dehydrogenation of the methyl groups. ${ }^{33}$

Substrate-dependent bonding configurations are known for other molecular adsorbates as well. A molecular orientation with the ring parallel with the surface (i.e. a "flat" bonding configuration) has been found for benzene on $\operatorname{Pd}(100),{ }^{34} \mathrm{Pt}$ (111), ${ }^{35} \mathrm{Rh}(111),{ }^{36} \operatorname{Ir}(111),{ }^{37} \mathrm{Ni}(111),{ }^{38-40}$ and $\mathrm{Ru}(100),{ }^{41}$ For benzene on $\operatorname{Pd}(110)^{42,43}$ the selection rules applied to the angle resolved photoemission measurements suggest that instead of lying "flat" the adsorption geometry is slightly tilted. A tilt geometry of $10^{\circ}-20^{\circ}$ was proposed, ${ }^{43}$ reducing the overall symmetry to $C_{s}$. Similarly, benzene on $\mathrm{Cu}(110)$ is also believed to be tilted ${ }^{44}$ to an even greater degree than the $10^{\circ}-20^{\circ}$ inferred for benzene on $\operatorname{Pd}(110)$.

The closely related molecule, pyridine, does not lie flat as readily as benzene. Angle-resolved photoemission measurements show quite clearly that the molecule bonds through the $\mathrm{N}$ atom on $\mathrm{Ir}$ (111). ${ }^{37}$ The molecule stands up (i.e., upright), occupying a relatively high point group symmetry in this bonding configuration, with the molecular axis along the surface normal. ${ }^{37}$ Angle-resolved photoemission results for pyridine on Pd(111) suggest a tilted configuration (neither "flat" nor "upright" in bonding configuration) with the molecule interacting with the surface through both the nitrogen lone pair electrons and the p electrons. ${ }^{45}$ Pyridine on $\operatorname{Pd}(110)$ appears from angleresolved photoemission to bond in a "flat" configuration. ${ }^{46}$ This is quite different from many of the results for the pyridine bonding configuration. Angle-resolved photoemission from this surface, $\operatorname{Pd}(110)$, has also provided unusual results for benzene, as we have just noted - the bonding of benzene on $\operatorname{Pd}(110)$ has been suggested to bond in a tilted configuration (opposite to most benzene bonding configurations). ${ }^{43}$

\section{Conclusion}

We find that ferrocene is weakly bound to $\mathrm{Ag}(100)$, consistent with earlier studies, ${ }^{5}$ and the preferential bonding orientation is with the molecular axis along the surface normal. Molecular ferrocene adsorption on $\mathrm{Cu}(100)$, on the other hand, bonds with the molecular axis parallel with the surface and a preferential orientation along the $\langle 110\rangle$ direction. Significantly, preliminary results indicate that the differing bonding modes give rise to differing rates of surface decomposition.

The vibrational modes in the HREELS measurements are reasonably well modeled with the extended basis set $(3-21 \mathrm{G})$ calculations. The infrared and Raman data available in the literature support our assignments of the vibrational modes from the HREELS data. Nevertheless, the high-frequency peaks require significant improvements in the calculations. We anticipate that the use of anharmonic force field would enhance the accuracy of the results and help us better model the vibrational modes for all the peaks in the HREELS spectrum of ferrocene.

Acknowledgment. This work was supported by the U.S. Department of Energy through Grant DE-FG0295ER12177.AOOO, the Division of Materials Sciences, U.S. Department of Energy, under Contract DE-AC05-96OR22464 with Lockeed Martin Energy Research Corp., and the donors of Petroleum Research Fund, administered by the American Chemical Society. The authors thank David Pugmire for his careful reading of the manuscript.

\section{References and Notes}

(1) Togni, A. Angew. Chem., Int. Ed. Engl. 1996, 35, 1475. Riant, O.; Samuel, O.; Kagan, H. B.; J. Am. Chem. Soc. 1993, 115, 5835. Tsukazaki, M.; Tiukl, M.; Rogans, A.; Capell, B. J.; Taylor N. J.; Snieckus, V.; J. Am. Chem. Soc. 1996, 118, 685. Nishibayashi, Y.; Arikawa, Y.; Ohe K.; Uemura, S.; J. Org. Chem. 1996, 61, 1172.

(2) Boag, N. M.; Dowben, P. A. Designing Organometallics for Vapor Phase Metallization of Plastics. Metallized Plastics 4: Fundamental and Applied Aspects; Mittal, K. L., Ed.; Plenum Press: New York, 1997. Dowben, P. A.; Spencer, J. T.; Stauf, G. T. Mater. Sci. Eng. 1989, B2, 297.

(3) Spencer, J. T. Prog. Inorg. Chem. 1994, 41 (Chapter 3), 1452376. Kodas, T.; Hampden-Smith, M. The Chemistry of Metal CVD; VCH Publishers: New York, 1994.

(4) Dormans, G. J. M. J. Cryst. Growth 1991, 108, 806.

(5) Welipitiya, D.; Dowben, P. A.; Zhang, J.; Pai, W. W.; Wendelken, J. F. Surf. Sci. 1996, 367, 20.

(6) Welipitiya, D.; Green, A.; Woods, J. P.; Dowben, P. A.; Robertson, B.; Byun, D.; Zhang, J. J. Appl. Phys. 1996, 79, 8730.

(7) Zanoni, R.; Piancastelli, M. N.; Marsi, M.; Margaritondo, G. J. Electron Spectrosc. Relat. Phenom. 1991, 57, 199.

(8) Dowben, P. A. Z. Phys. Chem., in press.

(9) Ueno, N. J. Electron Spectrosc. Relat. Phenom. 1996, 78, 345.

(10) Ueno, N.; Suzuki, K.; Hasegawa, S.; Kamiya, K.; Seki, K.; Inokuchi, H.; J. Chem. Phys. 1993, 99, 7169. Hasegawa, S.; Tanaka, S.; Tamashita, Y.; Inokuchi, H.; Fujimoto, H.; Kamiaya, K.; Seki, K.; Ueno, N. Phys. Rev. 1993, B48, 2596. Yamashita, Y.; Tanaka, S.; Imaeda, K.; Inokuchi, H. Chem. Phys. Lett. 1991, 7, 1213. Horowitz, G.; Peng, X.; Fichou, D.; Ganier, F. J. Appl. Phys. 1990, 67, 528. Ishii, H.; Nariaka, S.; Edamatsu, K.; Kamiya, K.; Hasegawa, S.; Ohta, T.; Ueno, N.; Seki, K. J. Electron Spectrosc. Relat. Phenom. 1996, 78, 395. Yannoulis, P.; Frank, K.-H.; Koch, E. E. Surf. Sci. 1991, 243, 58. Yannoulis, P.; Frank, K.-H.; Koch, E.-E. Surf. Sci. 1991, 241, 325.

(11) Lee, S.; Li, D.; Dowben, P. A.; Perkins, F. K.; Onellion, M.; Spencer, J. T. J. Am. Chem. Soc. 1991, 113, 8444. Zeng, H.; Byun, D.; Zhang, J.; Vidali, G.; Onellion, M.; Dowben, P. A. Surf. Sci. 1994, 313, 239.

(12) Permien, T.; Engelhardt, R.; Feldmann, C. A.; Koch, E. E. Chem. Phys. Lett. 1983, 98, 527. Karmiya, K.; Momose, M.; Kitamura, A.; Harada, Y.; Ueno, N.; Miyazaki, T.; Hasegawa, S.; Inokuchi, H.; Narioka, S.; Ishii, H.; Seki, K. Mol. Cryst. Liq. Cryst. 1995, 267, 211. Richardson, Chem. N. V. Phys. Lett. 1983, 102, 390.

(13) Dowben, P. A.; LaGraffe, D.; Onellion, M. J. Phys.: Condens. Matter 1989, 1,6571 .

(14) Gaussian 92, Revision G.3: Frisch, M. J.; Trucks, G. W.; Schlegel, H. B.; Gill, P. M. W.; Johnson, B. G.; Wong, M. W.; Foresman, J. B.; 
Robb, M. A.; Head-Gordon, M.; Replogle, E. S.; Gomperts, R.; Andres, J. L.; Raghavachari, K.; Binkley, J. S.; Gonzalez, C.; Martin, R. L.; Fox, D. J.; Defrees, D. J.; Baker, J.; Stewart, J. J. P.; Pople, J. A. Gaussian Inc., Pittsburgh, PA, 1993

(15) Hehre, W. J.; Radom, L.; Schleyer, P. V. R.; Pople, J. A. Ab Initio Molecular Orbital Theory, Wiley-Interscience: New York, 1985.

(16) Bagus, P. S.; Waldren, U. I.; Almlof, J. J. Chem. Phys. 1976, 64, 2324.

(17) Coutiere, M.-M.; Demuynck, J.; Veillard, A. Theor. Chim. Acta 1972, 27, 281

(18) Rösch, N.; Johnson, K. H. Chem. Phys. Lett. 1974, 24, 179.

(19) Rösch, N.; Jörg, H. J. Chem. Phys. 1986, 84, 5967.

(20) Baerends, E. J.; Ros., P. Chem. Phys. Lett. 1973, 23, 341.

(21) Kirchner, R. F.; Loew, G. H.; Mueller-Westerhoff, U. T. Theor. Chim. Acta 1976, 41, 1 .

(22) Armstrong, D. R.; Fortune, R.; Perkins, P. G. J. Organomet. Met. Chem. 1976, 111, 197.

(23) Evans, S.; Green, M. L. H.; Jewitt, B.; King, G. H.; Orchard, A. F. J. Chem. Soc., Faraday Trans. 2 1973, 356. Evans, S.; Green, M. L. H.; Jewitt, B.; Orchard, A. F.; Pygall, C. F. J. Chem. Soc., Faraday Trans. 2 1972, 68, 1847.

(24) Vondrak, T. J. Organomet. Chem. 1984, 275, 93.

(25) Rabalais, J. W.; Werme, L. O.; Bergmark, T.; Karson, L.; Hussain, M.; Siegbahn, K. J. Chem. Phys. 1972, 57, 1185.

(26) Driscoll, D. C.; Dowben, P. A.; Boag, N. M.; Grade, M.; Barfuss, S. J. Chem. Phys. 1986, 85, 4802. Barfuss, S.; Grade, M.; Hirschwald, W.; Rosinger, W.; Boag, N. M.; Driscoll, D. C.; Dowben, P. A. J. Vac. Sci. Technol. 1987, A5, 1451.

(27) Cauletti, C.; Green, J. C.; Kelly, M. R.; Powell, P.; van Tilborg, J.; Robbins, J.; Smart, J. J. Electron Spectrosc. Relat. Phenom. 1980, 19, 327.

(28) Lippincott, E. R.; Nelson, R. D. Spectrochim. Acta 1958, 10, 307R.

(29) Schettino, V.; Marzocchi, M. P.; Califano, S. J. Chem. Phys. 1969, 51,52645 .
(30) Hyams, I. J. Spectrochim. Acta 1973, 29A, 839.

(31) Aleksanyan, V. T.; Greenwald, I. I. J. Mol. Struct. (THEOCHEM) 1982, 90, 35. Aleksanyan, V. T.; Arsen'eva, T. I.; Vishinsky, N. N.; Greenwald, I. I.; Smirnov, A. S. Isv. Akad. Nauk SSR Ser. Kim. 1981, 297.

(32) Pugmire, D.; Woodbridge, C.; Langell, M. Manuscript in preparation.

(33) Wilk, D. E.; Stanners, C. D.; Shen, Y. R.; Somorjai, G. A. Surf. Sci. 1993, 280, 298

(34) Hoffman, P.; Horn, K.; Bradshaw, A. M. Surf. Sci. 1981, 105, L260. Nyberg, G. L.; Richardson, N. V. Surf. Sci. 1979, 85, 335.

(35) Freund, H. J.; Eberhardt, W.; Heskett, D.; Plummer, E. W. Phys. Rev. Lett. 1983, 50, 768

(36) Neumann, M.; Mack, J. U.; Bertel, E.; Netzer, F. P. Surf. Sci. 1985 155, 629. Bertel, E.; Rosina, G.; Netzer, F. P. Surf. Sci. 1986, 172 L515.

(37) Mack, J. U.; Bertel, E.; Netzer, F. P. Surf. Sci. 1985, 159, 265.

(38) Huber, W.; Steinrück, H.-P.; Pache, T.; Menzel, D. Surf. Sci. 1991, $217,103$.

(39) Huber, W.; Zebisch, P.; Bornemann, T.; Steinrück, H.-P. Surf. Sci. 1991, 258, 16.

(40) Steinrück, H.-P. Appl. Phys. 1994, A59, 517.

(41) Heimann, P. A.; Jacob, P.; Pache, T.; Steinrück, H.-P.; Menzel, D. Surf. Sci. 1989, 210, 282.

(42) Netzer, F. P.; Vacuum 1990, 41, 49.

(43) Netzer, F. P.; Rangelov, G.; Rosina, G.; Saalfeld, H. B.; Neumann, M.; Lloyd, D. R. Phys. Rev. 1988, B37, 10399.

(44) Lomas, J. R.; Baddeley, C. J.; Tikhov, M. S.; Lambert, R. M. Chem. Phys. Lett. 1996, 263, 591.

(45) Netzer, F. P.; Mack, J.-U. Chem. Phys. Lett. 1983, 95, 492.

(46) Netzer, F. P.; Rangelov, G.; Rosina, G.; Saalfeld, H. B. J. Chem. Phys. 1988, 89, 3331.

(47) Brunvoll, J.; Cyvin, C. J.; and Schäfer, L. J. Organomet. Chem. 1971, 27, 107 . 